\title{
Effect of Using Breakfast Cereals on Reducing Weight and Body Mass Index in Obese and Over-Weight Individuals
}

\author{
Borzoei A.* MSc, Sohrabi Sh. ${ }^{1} M D$ \\ *Nutrition Faculty, Tabriz University of Medical Sciences, Tabriz, Iran \\ ${ }^{1}$ Social Health Office, Tehran Municipal, Tehran, Iran
}

\begin{abstract} level of weight loss by using a cereal diet for breakfast. Whitney $\mathrm{U}$ and independent $\mathrm{T}$ tests. sizes was non-significant between two groups. patients without any side effects.

Keywords

Cereals [http://www.ncbi.nlm.nih.gov/mesh/68002523];

Diet [http://www.ncbi.nlm.nih.gov/mesh/68004032];

Body Mass Index [http://www.ncbi.nlm.nih.gov/mesh/68015992];

Body Weight [http://www.ncbi.nlm.nih.gov/mesh/68001835]
\end{abstract}

Aims: Nowadays, the prevalence of obesity is increasing, not only in developed but also in developing countries. Using an alternative meal in a day is one of the most popular diets. The objective of the current research was to investigate the

Materials \& Methods: In this interventional study which was done in February 2013, 120 obese and overweight patients, who were referred to the Tehran Municipal Health House, randomly assigned to control and experimental groups. 30 to 45 grams of cereal with one glass of milk were prescribed for experimental group for breakfast and dinner and the control group had their regular diet. All samples were weighed, after 14 days period of study under the control of nutrition experts. The obtained data were analyzed by Mann-

Findings: Mean weight of both groups was decreased after the intervention. The decreasing was significant in experimental and non-significant in control group. Mean difference of decreasing in Body Mass Index $(\mathrm{p}=0.005)$ and weight $(p=0.078)$ parameters was significant and in waist $(p=0.63)$ and hips $(p=0.55)$

Conclusion: Using breakfast cereals is effective in reducing weight in obese

*Corresponding Author

Tel: +982188996659

Fax: +982166978677

Address: DAZCo Office, Unit 10, $5^{\text {th }}$ Floor, No. 54, 16 Azar Street, Keshavarz Boulevard, Tehran, Iran

s_borzoie@yahoo.com

Received: October 19, $2014 \quad$ Accepted: June 24, 2015 ePublished: September 20, 2015 
بيش از ·. باميليون نفر خاق هستند كه اين شيوع خاقى محدود به

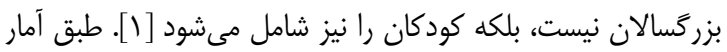

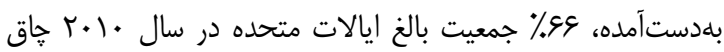

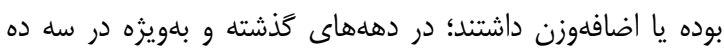

آخر قرن بيسته، كودكان خاق تا سه برابر افزايش يافتهاند [ب].

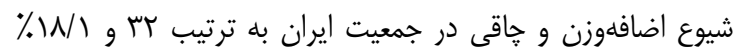

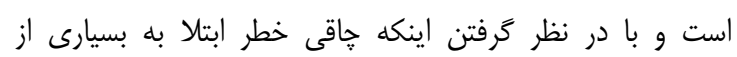

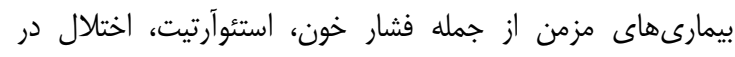

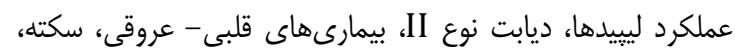

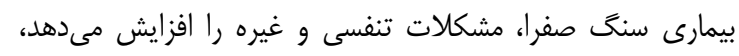

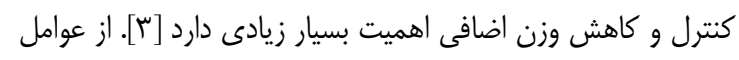

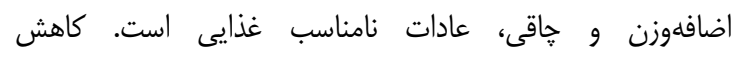

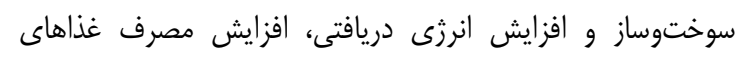

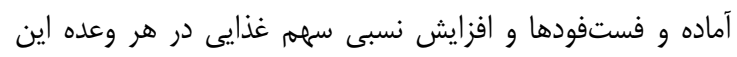

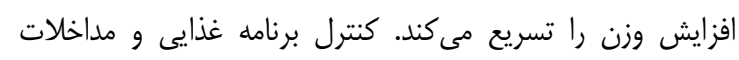

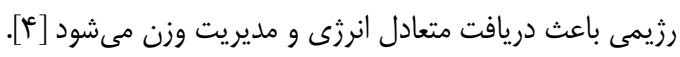

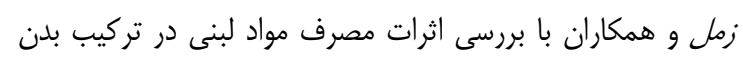

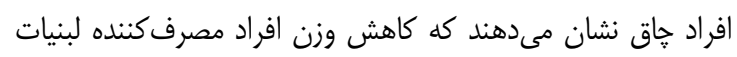

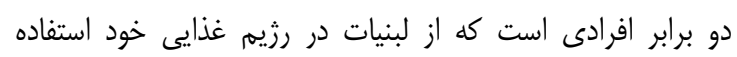

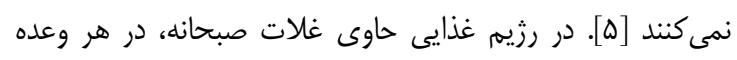

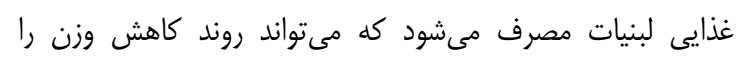
تسريع كند. ريجارد با بررسى تاثير مصرف غلات صنات صبحانه بلهعنوان جايكزين

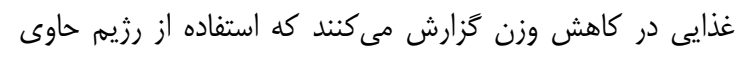

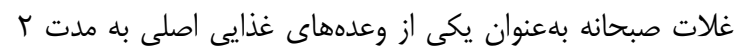

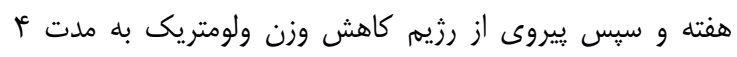

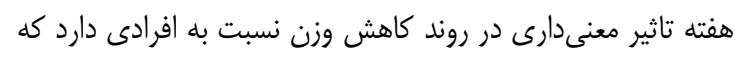

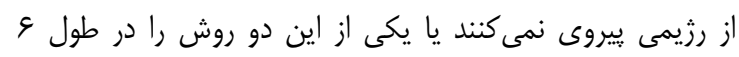
هفته انجام مى دهند [ع] كئل براساس نتايج سيدقلعه و همكاران، ارتباط معكوس و معنى داردى

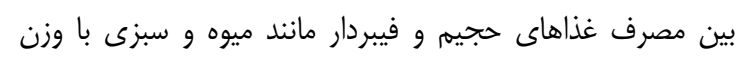

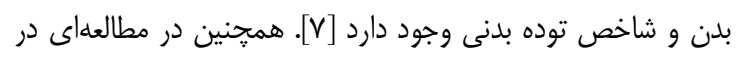

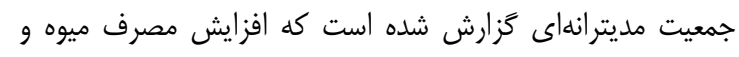

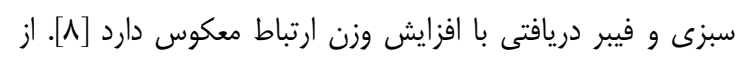

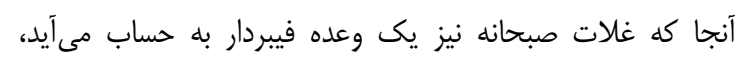

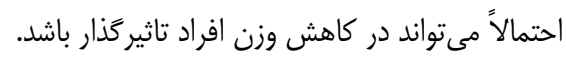

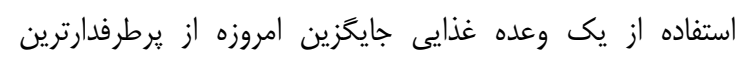

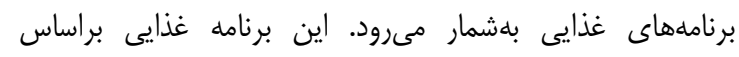

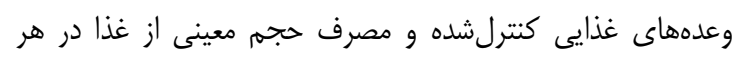

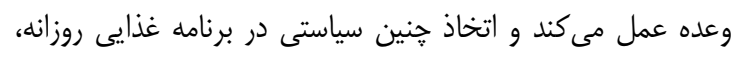

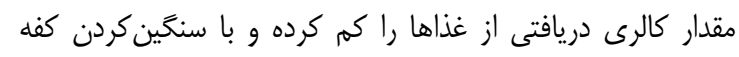

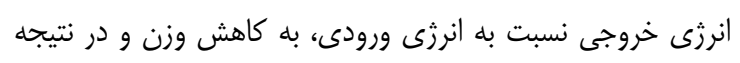

\section{تاثير مصرف غلات صبحانه در كاهش وزن وزن و ونام شاخص توده بدنى افراد جاق و داراى اضافه وزن}

MSc "اعظم برزويى

دانشكده تخذيه، دانشگاه علوم يزشكى تبريز، تبريز، ايران

MD شهرام سهر ابى

اداره سلامت اجتماعى، شهردارى تهران، تهران، ايران

جكيده

اهداف: امروزه شيوع خاقى نهتنها در كشورهاى توسعليافته، بلكه در

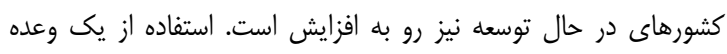

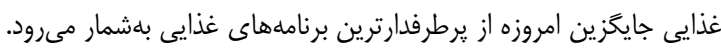

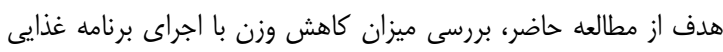

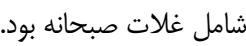

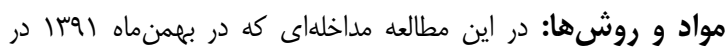

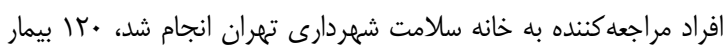

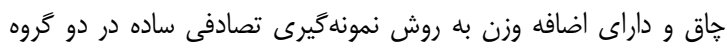

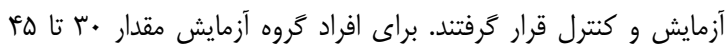

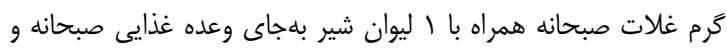

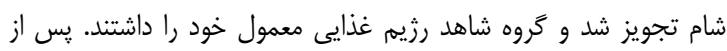

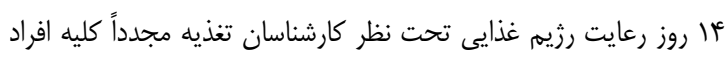

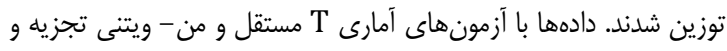
تحليل شدند.

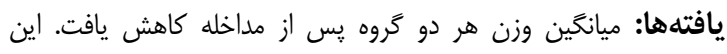

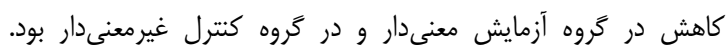

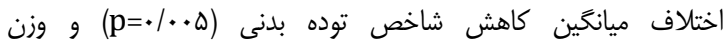
(p=•/•lv)

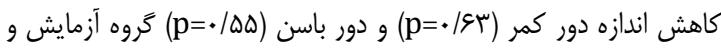
كروه كنترل غيرمعنى دار بود.

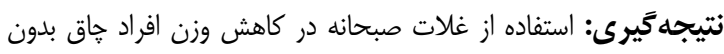
ايجاد عوارض جانبى موثر است. كليدوازهها: غلات صبحانه، رزيم غذايى، شاخص توانده إنه بدنى، وزن

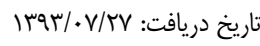

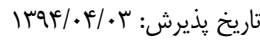

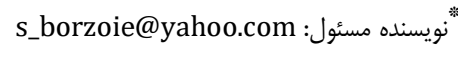

مقدمه

جاقى عبارت از تجمع جربى اضافه در بدن است كه در اثر عوامل

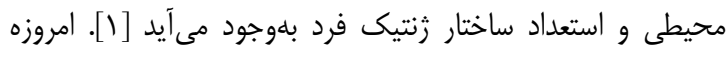

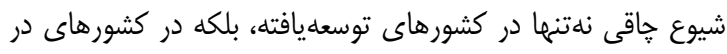

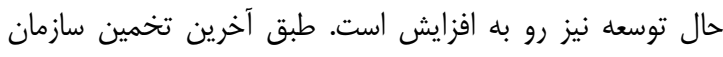

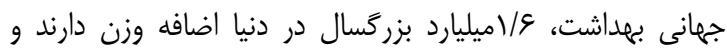


IVV تاثير مصرف غلات صبحانه در كاهش وزن و شاخص توده بدنى افراد حاق و داراى اضافه وزن

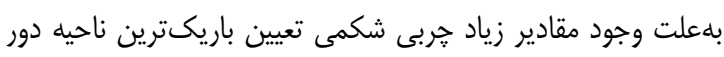

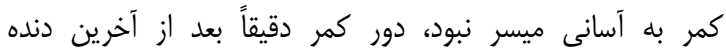

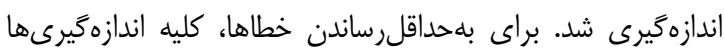

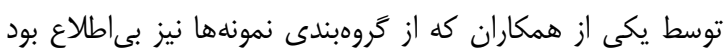

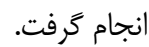

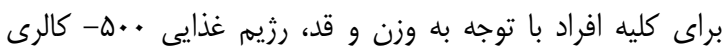

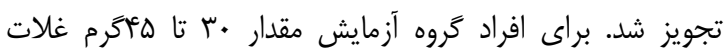

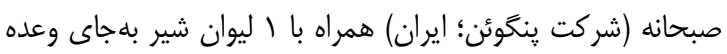

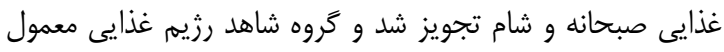

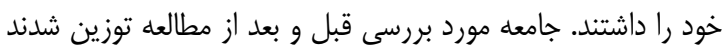

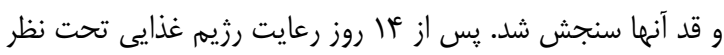

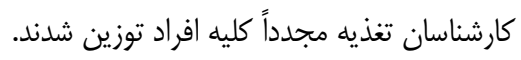

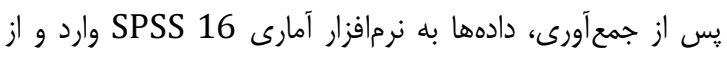

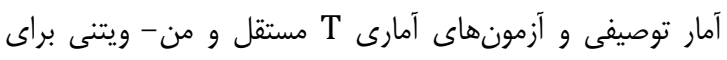
تجزيه و تحليل دادهها استفاده شد.

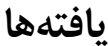

ميانكين سن افراد كروه آزمايش

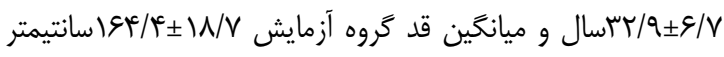

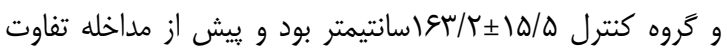

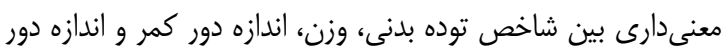

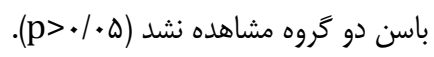

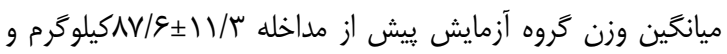

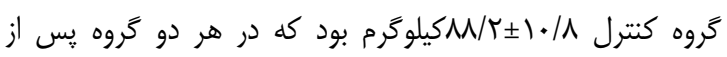

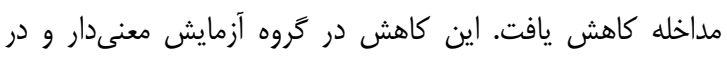
كروه كنترل غيرمعنى دار بود (جدول ().

\begin{tabular}{|c|c|c|c|c|}
\hline & ر دو گروه & يس از مداخله & باسن يِيش & \\
\hline دور باسنى متر) & (سانتى متر) & 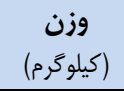 & شوده بدنى & تروه \\
\hline$|r r / \varepsilon \pm r| r / r$ & $\wedge 9 / f \pm I V / \varepsilon$ & $\Lambda V / \mathcal{A}_{ \pm} \| / / \Gamma$ & $r \tau / V \pm F / T$ & آزيش ازيش مداخله \\
\hline $\mid r / 9 \pm 19 / 1$ & $\Lambda N / \Lambda \pm 1 Q / q$ & $\Lambda \leftarrow / \Delta \pm 1 \cdot / \uparrow$ & $T / / \Delta \pm r / T$ & پِ از مداخله \\
\hline $\mathrm{p}=\cdot / \mu \Delta$ & $\mathrm{p}=\cdot / \pi r$ & $p=\cdot / . r$ & $\mathrm{p}=\cdot / \cdot 1$ & سطح معنى دارى \\
\hline & & & & كنترل \\
\hline $\mid r F / \cdot \pm r \cdot / \Delta$ & 19/8 $\pm 18 / 9$ & $M N / r \pm 1 \cdot / \Lambda$ & $\Gamma / \mu \pm \tilde{T} / \Delta$ & يِش از مداخله \\
\hline $\mid r \mu / E \pm r \cdot / r$ & $\Lambda 9 / r \pm 1 N / 1$ & $\wedge V / r \pm 1 \cdot / V$ & $r T / q \pm r / l$ & پِ از مداخله \\
\hline $\mathrm{p}=\cdot / /^{\mathrm{c}} \mathrm{V}$ & $\mathrm{p}=\cdot / \pi$ & $\mathrm{p}=\cdot / \mathrm{Ir}$ & $\mathrm{p}=\cdot / \mathbb{F}^{\circ}$ & سطح معنى دارى \\
\hline
\end{tabular}

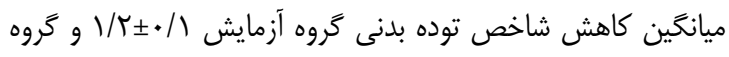

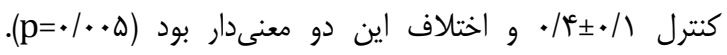

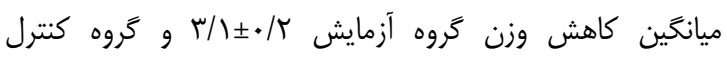

حفظ سلامتى و شادابى منجر شود [ع]. برنامه غذايى كاهش وزن

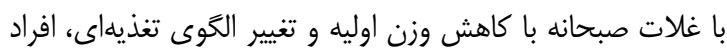

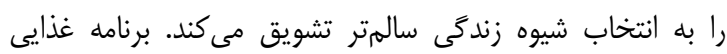

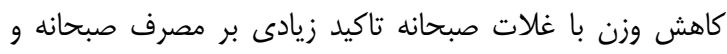

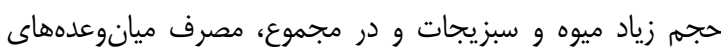

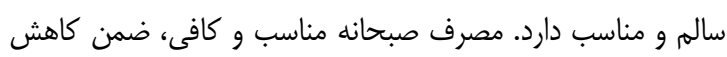

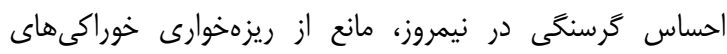

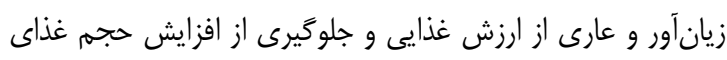

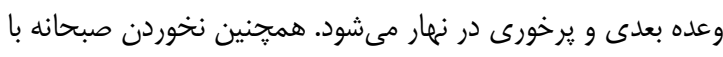

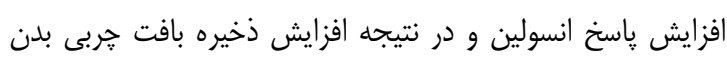

همراه است [9].

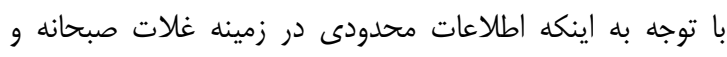

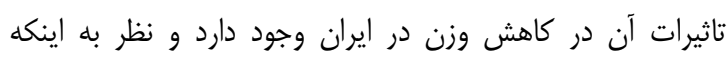

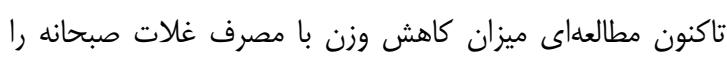

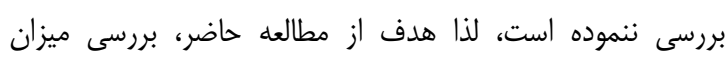
كاهش وزن با اجراى برنامه غذايى شامل غلات لنات صبحانه بود.

\section{مواد و روشها}

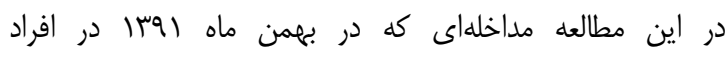

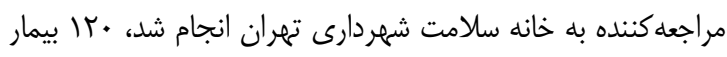

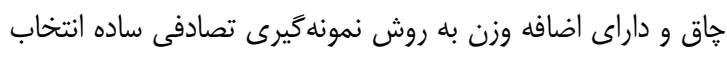

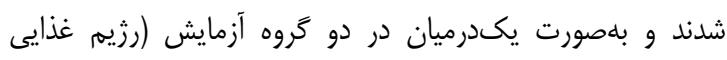

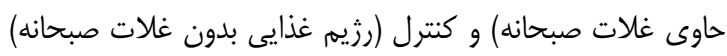

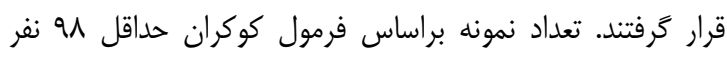

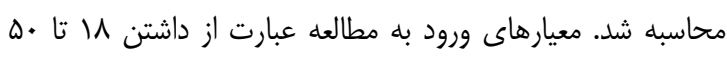

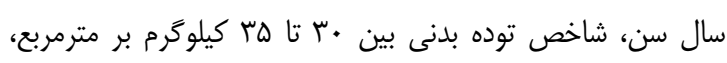

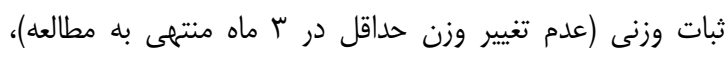

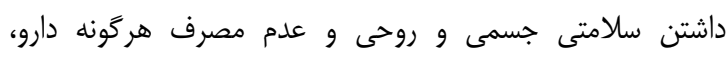

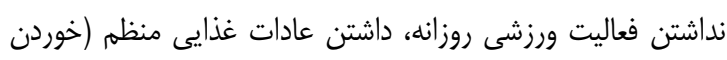

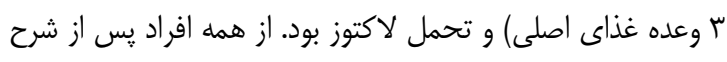

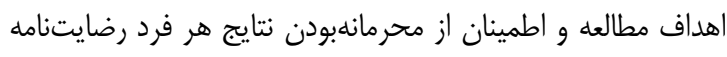

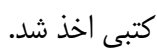
دادهايى جمعيتشناختى شامل جنات جنسيت، سن، سابقه مصرف

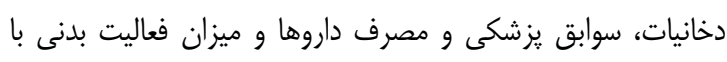

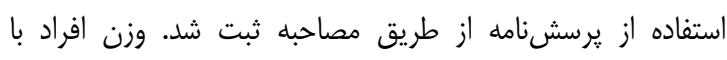

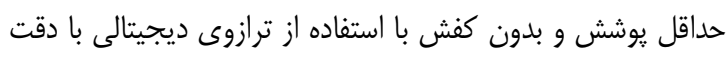

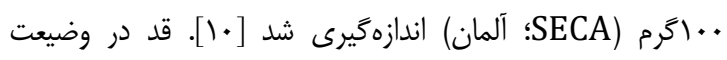

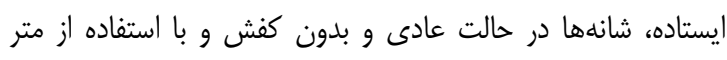

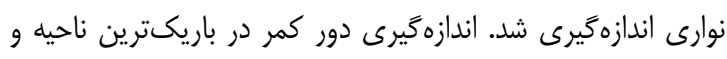

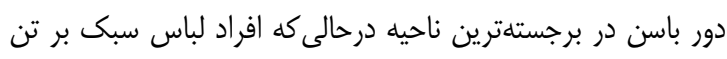

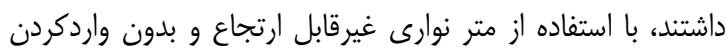
هركَونه فشار به بدن و با دقت / / • سانتيمتر انجام شد. ازآنجاكه 
مى شود و سبك زندگى است. بنابراين، بازنخرى و اصلاح در برنامه

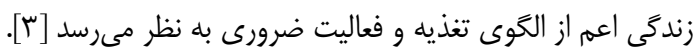
حذف صبحانه بdعنوان راهى براى كاهش كالرى دريافتى هيج تاثيرى بر كاهش وزن ندارد و حتى نخوردن صبحانه باعث جاقى بـى مىشود [ع]. اين برنامه كه جندين سال در تمام دنيا و بهخصوص

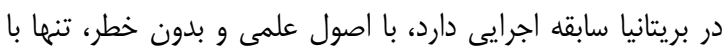

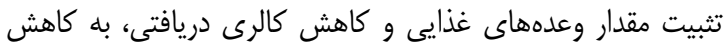

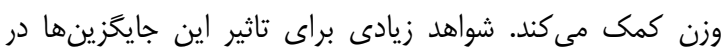

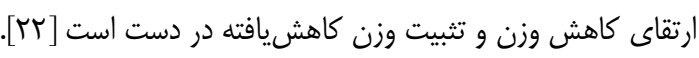

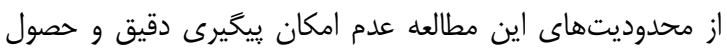

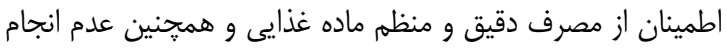

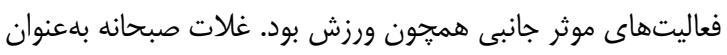

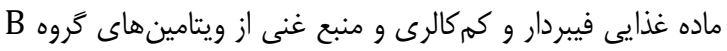

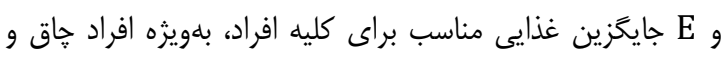

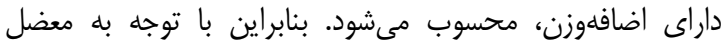

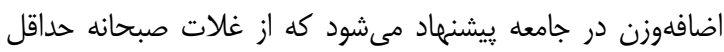
بهعنوان يكى از ميانوعدهها در رزيم غذايى استفاده شود.

\section{نتيجه كَيرى}

استفاده از غلات صبحانه در كاهش وزن افراد جاق بدون ايجاد عوارض جانبى موثر است.

تشكر و قدردانى: نويسندكان بر خود لازم مىداند كُ كه از

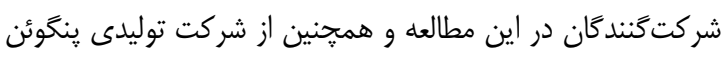

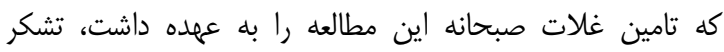

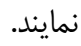

تاييديه اخلاقى: تمامى شركتكنندكان بهصورت آكاهانه و با نماينا رضايت در مطالعه شركت نمودند. تعارض منافع: هيجِكونه تعارض منافع ناشى از يشتيبانى مالى درد اين مطالعه وجود نداشته است. منابع مالى: اين مطالعه توسط خانه سلامت شهردارى تهران يشتيبانى شده است.

\section{منابع}

1- Bouchard C. Childhood obesity: Are genetic differences involved?. AM J Clin Nutr. 2009;89(5):1494S501S.

2- Arnold J, Jánoska M, Kajon AE, Metzgar D, Hudson NR, Torres S, et al. Genomic characterization of human adenovirus 36, a putative obesity agent. Virus Res. 2010;149(2):152-61.

3- Van Ginneken V, Sitnyakowsky L, Jeffery JE. Infectobesity: viral infectious (especially with human adenovirus-36: Ad-36) may be a cause of obesity. Med Hypotheses. 2009;72(4):383-8.

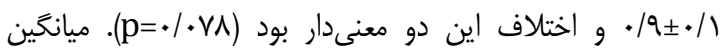

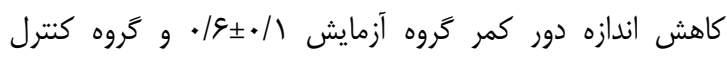

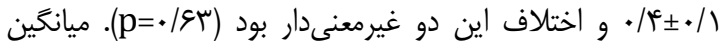

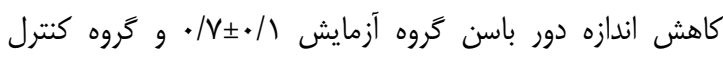

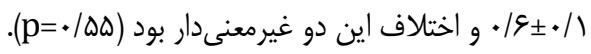

\section{بحث}

در اين مطالعه كه با هدف بررسى ميزان كاهش وزن بان اجراي

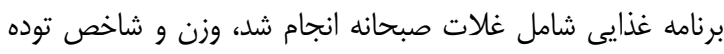

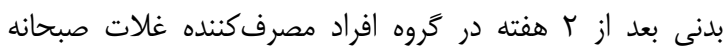

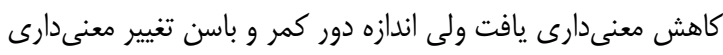
نداشت كه با نتايج برخى مطالعات همسو است. مطالعات النات بسيار

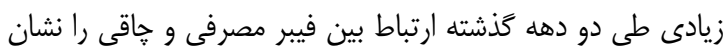

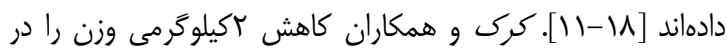

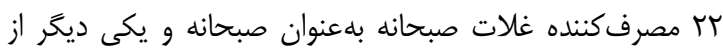

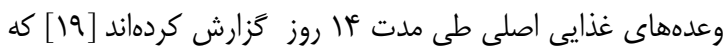

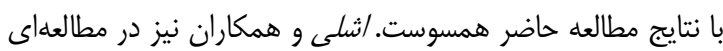

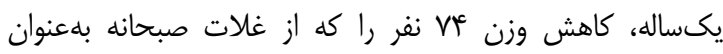

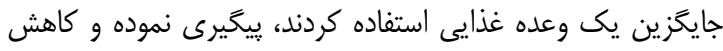

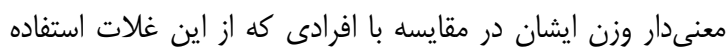

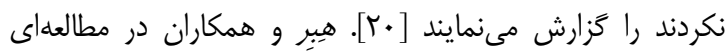

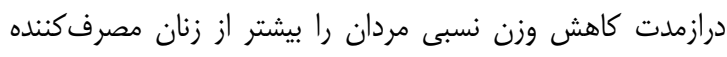

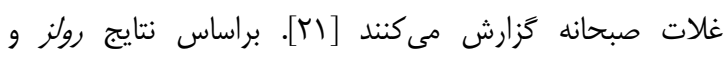

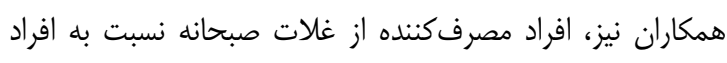

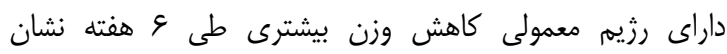

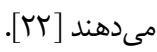
غلات صبحانه داراى فيبر زياد است و از جمله مواد مواد غذايى

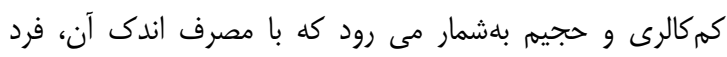

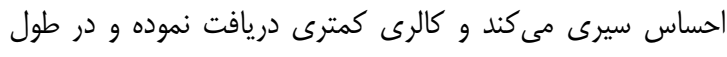

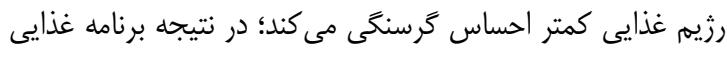

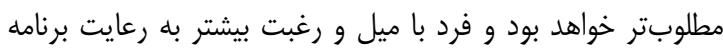

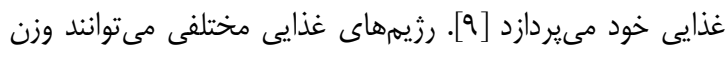

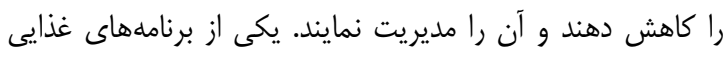

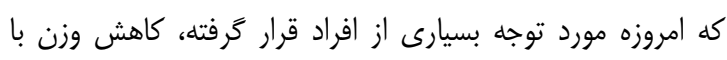

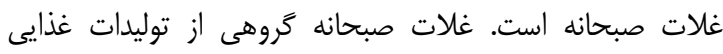

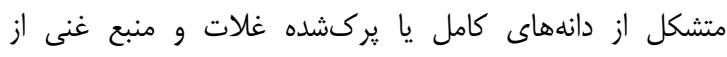

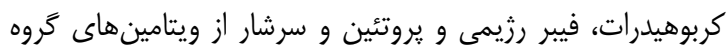

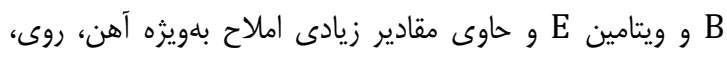

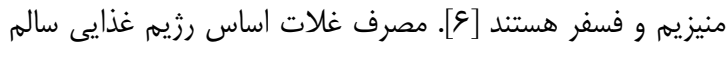

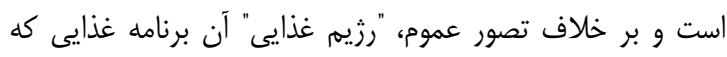

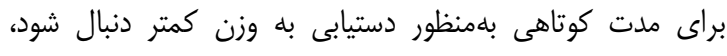

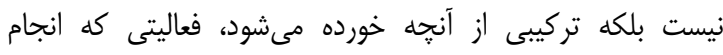
دوره آ، شماره r، ياييز سو فصلنامه افق دانش 
IV9 تاثير مصرف غلات صبحانه در كاهش وزن و شاخص توده بدنى افراد حاق و داراى اضافه وزن IV9

fibers on disturbances clustered in the metabolic syndrome. J Nutr Biochem. 2008;19(2):71-84.

14- Kimm SY. The role of dietary fiber in the development and treatment of childhood obesity. Pediatrics. 1995;96(5 Pt 2):1010-4.

15- Kring SI, Heitmann BL. Fiber intake, not dietary energy density, is associated with subsequent change in BMI z-score among sub-groups of children. Obes Facts. 2008;1(6):331-8.

16- Bulló M, Casas-Agustench P, Amigó-Correig $\mathrm{P}$, Aranceta J, Salas-Salvadó J. Inflammation, obesity and comorbidities: the role of diet. Public Health Nutr. 2007;10(10A):1164-72.

17- Babio N, Bulló M, Salas-Salvadó J. Mediterranean diet and metabolic syndrome: The evidence. Public Health Nutr. 2009;12(9A):1607-17.

18- Holst-Schumacher I, Nuñez-Rivas H, Monge-Rojas R, Barrantes-Santamaría M. Components of the metabolic syndrome among a sample of overweight and obese Costa Rican schoolchildren. Food Nutr Bull. 2009;30(2):161-70.

19- Kirk T, Crombie N, Cursiter M. Promotion of dietary carbohydrate as an approach to weight maintenance after initial weight loss: a pilot study. J Hum Nutr Diet. 2000;3:277-85.

20- Ashley JM, St Jeor ST, Perumean-Chaney S, Schrage J, Bovee V. Meal replacements in weight intervention. Obes Res. 2001;9(Suppl 4):312S-20S.

21- Heber D, Ashley JM, Wang HJ, Elashoff RM. Clinical evaluation of a minimal intervention meal replacement regimen for weight reduction. J Am Coll Nutr. 1994;13(6):608-14.

22- Rolls BJ, Rowe EA, Rolls ET, Kingston B, Megson A, Gunary R. Variety in a meal enhances food intake in man. Physiol Behav. 1981;26(2):215-21.
4- Bowen J, Noakes M, Clifton PM. A high dairy protein, high-calcium diet minimizes bone turnover in overweight adults during weight loss. J Nutr. 2004;134:568-73.

5- Zemel MB, Thompson W, Milstead A, Morris K Campbell P. Calcium and diary acceleration of weight and fat loss during energy restriction in obese adults. Obes Res. 2004;12(4):582-90.

6- Richard DM. Ready-to-eat cereal used as a meal replacement promotes weight loss in humans. J Am Coll Nutr. 2002;21:570-7.

7- Seyed Ghalaeh R, Gholi Z, Saraf Bank S, Azadbakht L. Fruit and Vegetable Intake Associated with Body Mass Index and Waist. J Educ Health Promot. 2012;1:29-34. [Persian]

8- Bes-Rastrollo M, Martinez-Gonzalez MA, SanchezVillegas A, dela Fuente Arrillaga C, Martinez JA. Association of fiber intake and fruit/vegetable consumption with weight gain in a Mediterranean population. Nutrition. 2006;225:504-11.

9- Quinn Rothacker D. Five-year self-management of weight using meal replacement: comparison with matched controls in rural Wisconsin. Nutrition. 2000;16(5):344-8.

10- Borzoie A, Azadbakht L. The dietary behavior of Isfahanian female youths: tea, fast food, fats and cooking methods. Health Sys Res J. 2010;6(4):1-8. [Persian]

11- Hazhir MS, Senobar Tahaei SN, Reshadmanesh N, Rashidi K. The effect of yoghurt on BMI and weight reduction in overweight people. Sci J Kurdistan Med Sci Uni. 2006;11(1):71-6. [Persian]

12- Lyon MR, Kacinik V. Is there a place for dietary fiber supplements in weight management?. Curr Obes Rep. 2012;1(2):59-67.

13- Galisteo M, Duarte J, Zarzuelo A. Effects of dietary 